\title{
Balencie J.-M. \& de La Grange A. (dir.), Les nouveaux mondes rebelles, conflits, terrorismes et contestations
}

Paris, Michalon, 2005, $503 \mathrm{p}$.

\section{Julien Vandeburie}

\section{(2) OpenEdition}

\section{Journals}

Édition électronique

URL : http://journals.openedition.org/belgeo/12226

DOI : $10.4000 /$ belgeo.12226

ISSN : 2294-9135

Éditeur :

National Committee of Geography of Belgium, Société Royale Belge de Géographie

Édition imprimée

Date de publication : 31 décembre 2005

Pagination : 520-521

ISSN : 1377-2368

Référence électronique

Julien Vandeburie, «Balencie J.-M. \& de La Grange A. (dir.), Les nouveaux mondes rebelles, conflits, terrorismes et contestations », Belgeo [En ligne], 4 | 2005, mis en ligne le 29 octobre 2013, consulté le 22 septembre 2020. URL : http://journals.openedition.org/belgeo/12226 ; DOI : https://doi.org/10.4000/ belgeo.12226

Ce document a été généré automatiquement le 22 septembre 2020.

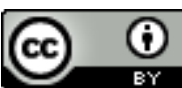

Belgeo est mis à disposition selon les termes de la licence Creative Commons Attribution 4.0 International. 


\section{Balencie J.-M. \& de La Grange A. (dir.), Les nouveaux mondes rebelles, conflits, terrorismes et contestations}

Paris, Michalon, 2005, 503 p.

Julien Vandeburie

\section{RÉFÉRENCE}

Balencie J.-M. \& de La Grange A. (dir.), Les nouveaux mondes rebelles, conflits, terrorismes et contestations, Paris, Michalon, 503 p.

1 Les mondes rebelles font peau neuve, ou plutôt muent et se multiplient. La troisième édition de l'encyclopédie des conflits n'est pas une mais multiple. Au volumineux ouvrage succèdent une version « réactive », qui est commentée ci-après, mais aussi une série d' "encyclopédies » (une par continent) sur le modèle des éditions précédentes et enfin une collection de monographies destinées à réagir aux éléments de rupture générés par l'actualité.

2 Le présent tome est donc, selon les auteurs, incomplet, même s'il apporte une somme d'informations déjà considérable. Les notices sont organisées par entrées géographiques ou thématiques: on retrouve des articles sur Al-Qaïda, les ONG humanitaires et la guerre, à propos du trafic de drogues illicites, du phénomène des «Maras » ou encore des réseaux djihadistes en Europe, le tout complété par un index très pratique.

La force des précédentes éditions est toujours présente même dans cette version raccourcie: une analyse fouillée et construite du conflit, un diagnostic précis des acteurs en présence, quelques statistiques clés et des pistes de lecture supplémentaires. Extrêmement bien documentés, les articles permettent une vision claire de la situation. Les commentaires font autorité et se démarquent de la pseudo production scientifique de nombreux «spécialistes ». Si l’on prend le cas de la République démocratique du 
Congo, l'article s'ouvre sur une carte de situation et un rappel de l'histoire politique congolaise depuis l'indépendance. Il détaille ensuite la chute du maréchal Mobutu Sese Seko et les raisons du succès de l'AFDL de Laurent-Désiré Kabila. L'impopularité de ce dernier, jointe à son incapacité à pacifier et à reconstruire le pays, à contenter ses alliés et à contenir ses adversaires conduiront à de nouvelles guerres à l'est du pays. Son assassinat et l'avènement au pouvoir de son fils constitueront un tournant dans l'évolution politique du Congo. Néanmoins les enjeux politiques, économiques et identitaires, tous extrêmement liés, restent des sujets brûlants dans les provinces d'Ituri et des Kivu. Certes, le dialogue intercongolais est amorcé, des signes de normalisation apparaissent mais la situation est toujours minée par des dissensions interrégionales et le jeu des seigneurs de la guerre.

4 L'ouvrage reste donc une source d'informations très utile pour les géographies des instabilités, plus agréable à la lecture qu'un rapport institutionnel et dont l'analyse se révèle d'une justesse éprouvée. Nous attendons avec intérêt les prochains volumes de la collection. 